\title{
ANÁLISE DAS ÁREAS DE PRESERVAÇÃO PERMANENTE dO PERÍMETRO URBANO DE OURO PRETO (MG)
}

\author{
Thiago Nogueira Lucon"; José Francisco do Prado Filho²; Frederico Garcia Sobreira ${ }^{3}$; \\ Cynthia Tange Bojikian ${ }^{4}$
}

(recebido em 19.06.2011 e aceito para publicação em 15.12.2011)

\section{RESUMO}

O crescimento e a velocidade de ocupação das áreas urbanas constituem uma preocupação constante dos profissionais ligados à questão urbano ambiental das cidades. Ouro Preto (MG) tem muitas das suas áreas legalmente protegidas suprimidas pela urbanização, reduzindo assim, a qualidade e quantidade dos recursos hídricos, a estabilidade geológica e a biodiversidade urbana. Este estudo, por meio de técnicas de geoprocessamento, identificou, quantificou e classificou o uso do solo das áreas de preservação permanente (APP) inseridas no perímetro urbano de Ouro Preto como estabelece o Código Florestal Brasileiro e complementado pela Lei Municipal no 93/2011. De acordo com os resultados obtidos, a cidade apresenta APP de $19,37 \mathrm{~km}^{2}$ representando $69 \%$ da área total. Dentre as APP no perímetro urbano, 19\% $\left(3,70 \mathrm{~km}^{2}\right)$ encontram-se antropizadas, constituído de áreas construídas (11\%), arruamentos (3\%) e solo exposto (5\%), favorecendo problemas como processos erosivos, instabilidade de terrenos e deslizamentos de massa, assoreamento dos corpos d'água e diminuição na qualidade dos recursos hídricos. O presente trabalho oferece dados para a administração municipal desenvolver políticas públicas locais que visem à preservação, conservação e recuperação dessas áreas, bem como subsídios à fiscalização dos usos irregulares e a promoção de ações de recuperação e intervenções visando à proteção geoambiental.

Palavras chaves: Áreas de preservação permanente (APP); Espaço Urbano; Ocupação de áreas protegidas; SIG.

\footnotetext{
${ }^{1}$. Biólogo especialista em Gestão Ambiental IFMG, mestrando pelo programa de Pós-Graduação em Engenharia Ambiental - UFOP, Morro do Cruzeiro s/n, CEP: 35400-000 Ouro Preto, MG. thiago lucon@hotmail.com

2. Ecólogo, Professor Doutor do DEAMB - UFOP, Ouro Preto, MG. jfprado@depro.em.ufop.br

3 . Geólogo, Professor Doutor do DEAMB - UFOP, Ouro Preto, MG. sobreira@degeo.ufop.br

4. Engenheira Geóloga DEGEO - UFOP, Ouro Preto, MG. cynthia_bojikian@yahoo.com.br
} 


\title{
AN EVALUATION OF THE ENVIRONMENTALLY PROTECTED AREAS WITHIN THE URBAN CENTER OF OURO PRETO (MG), BRAZIL
}

\begin{abstract}
The fast pace of urban sprawling over natural areas has long been a concern of professionals in the fields of urban and environmental planning. Ouro Preto (MG) is not an exception in Brazil. Relevant portions of its environmentally protected areas have been affected by urban projects, which have, in turn, negatively impacted water resources, geological stability, biodiversity, the health and well-being of the population. Based on geoprocessing techniques, this study has quantified and classified the land uses within environmentally protected areas in the urban center of Ouro Preto, as required by the Brazilian Forest Act (N. 4771/1965) and the Municipal Ordinance N. 93/2011. Findings indicate that the urban center has $19,37 \mathrm{~km}^{2}$ of environmentally protected areas, which accounts for $69 \%$ of total urban center. Within these protected areas, $19 \%\left(3,7 \mathrm{~km}^{2}\right)$ is already urbanized by buildings (11\%), roads $(3 \%)$ and exposed land $(5 \%)$, thus triggering soil erosion, geological instability, landslides, siltation and water pollution. This study presents data that can be used in local public policy-making targeting preservation, conservation and rehabilitation of legally protected areas, especially in urban centers. The data presented here can also be used in the context of local inspection and land rehabilitation and reclamation programs.
\end{abstract}

Keywords: Environmentally Protected Areas; Urban sprawling; Land use evaluation; GIS.

\section{INTRODUÇÃO}

A cidade de Ouro Preto (MG) é uma das mais importantes cidades históricas do período colonial do Brasil, conhecida internacionalmente e considerada Patrimônio Cultural da Humanidade desde 1980 pela United Nations Educational, Scientific and Cultural Organization (Unesco). Ouro Preto possui no perímetro urbano um conjunto arquitetônico colonial muito bem conservado do século XVIII, exibindo entre suas ruas estreitas e ladeiras tortuosas, magníficos exemplares da arquitetura religiosa e civil, além de diversas atrações históricas, artísticas e naturais. Devido à falta de um planejamento urbano, a ocupação que

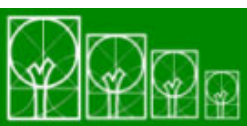

$\mathbf{S} \cdot \mathbf{B} \cdot \mathbf{A} \cdot \mathbf{U}$ Soc. Bras. de Arborização Urbana

REVSBAU, Piracicaba - SP, v.6, n.4, p.107-124, 2011 
a cidade vem adquirindo há algumas décadas propiciou o aparecimento de inúmeros problemas relacionados à má utilização do espaço, ferindo a harmonia das relações entre o meio biótico e abiótico, ignorando e suprimindo diversas áreas verdes, inclusive as legalmente protegidas (áreas de preservação permanente - APP).

De acordo com Lima Neto et al. (2007) a degradação das paisagens está assumindo proporções insustentáveis no que diz respeito tanto à quantidade como a qualidade da vegetação e suas funções ecológicas, econômicas e sociais o que acaba por influenciar diretamente na qualidade de vida das populações urbanas.

As áreas verdes urbanas atuam potencialmente na manutenção de aspectos associados à qualidade ambiental como provedora de benefícios ao homem interferindo positivamente na qualidade de vida pela manutenção das funções ambientais, sociais e estéticas. Tais benefícios amenizam significativamente a gama de consequências negativas da urbanização. Autores como Milano (1990, 1992, 1994); Detzel (1992, 1994); Sattler (1992); Cavalheiro (1992, 1994); Goya (1994); Henke-Oliveira (1996); Guzzo (1999); Silva Filho e Bortoleto (2005); Metzger et al. (2010); e Ab'Sáber (2010), enfatizam os benefícios da vegetação urbana, abordando a sua importância para o solo, umidade, nebulosidade, vento, pluviosidade, controle climático, da poluição do ar e acústica, melhoria estética, efeitos sobre a saúde física e mental da população, aumento do conforto ambiental, valorização de áreas para convívio social, valorização econômica das propriedades, conservação da biodiversidade (flora e fauna), entre outros.

De acordo com o Código Florestal, Lei Federal 4.771 (BRASIL, 1965), nas áreas de preservação permanente a vegetação deve ser mantida intacta, tendo em vista garantir a preservação dos recursos hídricos, da estabilidade geológica e da biodiversidade, bem como o bem-estar da população humana. As matas ciliares das nascentes, rios, córregos, lagos e reservatórios, a vegetação ocorrente nas localidades com declividade acentuada (maior que $45^{\circ}$ ) e nos topos de morro, são algumas das áreas de preservação permanente (APP) abordadas neste estudo.

É importante notar que os problemas relacionados à ocupação urbana se repetem, e estão sempre relacionados à má utilização do meio físico. Para citar Sobreira e Fonseca (2001, p.15) "os problemas existentes na cidade de Ouro Preto, [...] não decorrem apenas das condições naturais desfavoráveis, mas também em parte considerável da má utilização do meio físico e da falta de planejamento e adoção de procedimentos regidos por critérios técnicos consagrados". Ademais, o processo de uso do solo desordenado do meio físico

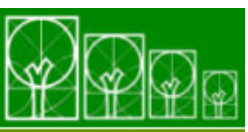

$\mathbf{S} \cdot \mathbf{B} \cdot \mathbf{A} \cdot \mathbf{U}$ Soc. Bras. de Arborização Urbana 
continua a avançar sobre outras estruturas, suprimindo as APP, reduzindo as áreas verdes da cidade e as benesses oriundas destas.

Este estudo tem como principal objetivo analisar, classificar e quantificar as áreas de preservação permanente relativas à declividade (áreas com declividade superior a $45^{\circ}$ ), topos de morros (o 1/3 superior relativo à cota máxima e a cota base do morro) e hidrografia (um raio de $50 \mathrm{~m}$ nas nascentes, e uma faixa de $30 \mathrm{~m}$ de rios, córregos, lagoas e represas) ocorrentes no perímetro urbano de Ouro Preto e suas relações com os aspectos do meio físico e biótico.

Os principais aspectos analisados do meio físico estão relacionados à rede hidrográfica, declividade e a geometria das vertentes, sempre observando a legislação pertinente, no caso o Código Florestal Brasileiro - Lei Federal n. 4.771/65 (BRASIL, 1965) complementado com a Lei Municipal n. 93 (OURO PRETO, 2011) que delimita o tamanho das áreas de preservação permanente no perímetro urbano. Para os aspectos bióticos, as áreas verdes foram classificadas em tipologias distintas com intuito de verificar, categorizar e quantificar a vegetação predominante nestas áreas protegidas. $O$ conjunto das análises propostas visa contribuir para a conservação dos recursos naturais e com o ordenamento territorial da cidade.

\section{Área de estudo}

O município de Ouro Preto está localizado na região central do Estado de Minas Gerais, mais especificamente no Quadrilátero Ferrífero. É circundado pelos municípios de Catas Altas da Noruega, Itaverava, Ouro Branco e Congonhas ao sul; Belo Vale e Moeda a oeste; Mariana a leste; Itabirito e Santa Bárbara ao norte. A área ocupada pelo município é de $1.245 \mathrm{~km}^{2}$ (IBGE, 2007). O perímetro urbano de Ouro Preto está localizado entre as coordenadas 7748000-7742000 Norte-Sul e 660000-652000 Leste-Oeste (Figura 1).

A figura 2 apresenta a distribuição dos $27,9 \mathrm{~km}^{2}$ da área de estudo $(A E)$, sendo 14,5 $\mathrm{km}^{2}$ distribuídos entre seus 38 bairros e $13,3 \mathrm{~km}^{2}$ constituídos de áreas verdes localizadas no perímetro urbano, porém não compreendidas dentro de nenhum dos bairros, formando uma zona de amortecimento ou cinturão verde no entorno destes.

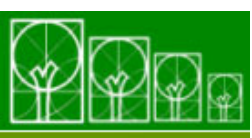

$\mathbf{S} \cdot \mathbf{B} \cdot \mathbf{A} \cdot \mathbf{U}$ Soc. Bras. de Arborização Urbana 
Figura 2. Representação gráfica da delimitação do perímetro urbano e distribuição das áreas compostas por bairros e cinturão verde ou zona de amortecimento que compõe o perímetro urbano de Ouro Preto

Figure 2. Graphic representation of the urban boundary and distribution of areas composed by neighborhoods and green belt or buffer zone that makes up the urban area of Ouro Preto

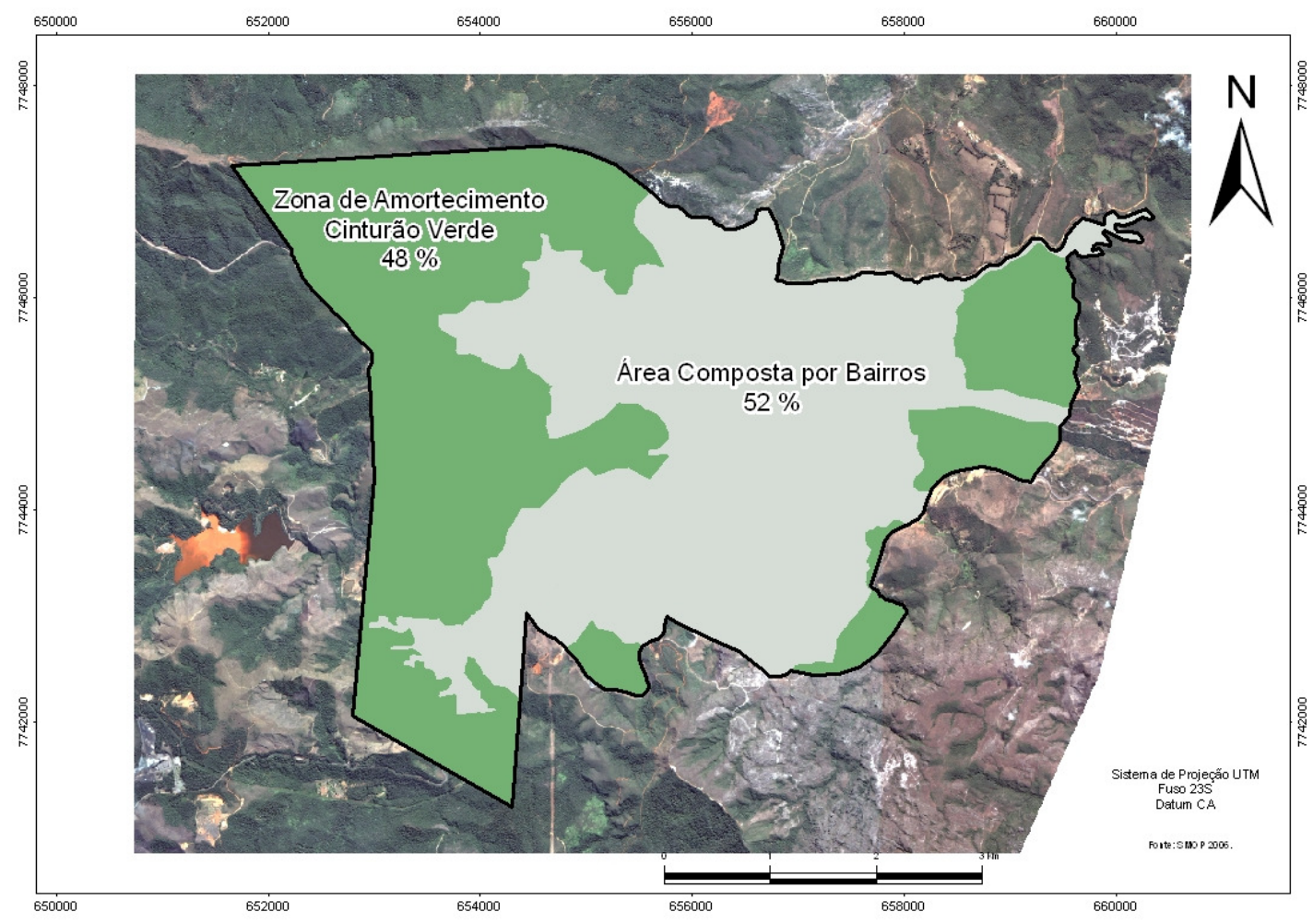

Na região de Ouro Preto e Mariana encontra-se um importante divisor de águas, a Serra de Ouro Preto, que divide duas grandes bacias hidrográficas, a do rio Doce e a do rio São Francisco, ambas com suas nascentes situadas no interior do Quadrilátero Ferrífero. O ribeirão do Carmo, uma das sub-bacias e nascentes do rio Doce, drena o perímetro urbano de Ouro Preto e Mariana até o município de Ponte Nova (MG), quando conflui com o rio Piranga, outra sub-bacia do rio Doce, transformando-se no alto rio Doce.

A bacia do rio do Carmo tem $2.280 \mathrm{~km}^{2}$ de área de drenagem e tem características de uma bacia alongada, com 132,3 km de comprimento axial e 17,2 km de largura média, que a torna pouco propensa a inundações (BARBOSA JR., 2006).

De acordo com a classificação estabelecida por Köppen, o clima de Ouro Preto corresponde ao tipo Cwb, clima úmido, com inverno seco e verão chuvoso, possui características básicas de clima de montanha. Os verões são suaves com elevada umidade 
atmosférica e os invernos são brandos com baixas temperaturas (OLIVEIRA, 2010). A média anual da temperatura é de $18,5^{\circ} \mathrm{C}$, variando entre $6^{\circ}$ e $2^{\circ} \mathrm{C}$. As temperaturas mais elevadas coincidem com o período chuvoso enquanto as temperaturas mais baixas ocorrem no período seco.

O regime pluviométrico é caracterizado como tropical, com uma média de 1610,1 mm anuais (série de 1988 a 2004, in CASTRO, 2006) devido à altitude elevada do município. A estação seca em Ouro Preto é marcada com umidades relativas variando de $78,7 \%$ nos meses de julho e agosto a 86,2\% no verão (IGA/CETEC, 1995).

A ocupação da região de Ouro Preto teve inicio nas primeiras décadas do século XVIII, coincidindo com o auge da corrida do ouro. Desde então, as transformações sofridas pela cidade, influenciadas pelo aumento da população e os assentamentos urbanos crescentes em conjunto com a falta de políticas públicas interferiram de maneira acelerada e intensa na estabilidade das encostas, causando graves problemas de movimentos de massa e escorregamentos, principalmente nos períodos chuvosos (SOBREIRA; FONSECA, 2001).

$\mathrm{Na}$ maioria das vezes, essas áreas de ocupação, em consequência da utilização passada, apresentam características morfológicas e geotécnicas desfavoráveis, gerando um quadro problemático no que se refere à segurança da população e das estruturas presentes (PINHEIRO et al., 2003).

\section{MATERIAIS E MÉTODOS}

As atividades desenvolvidas seguiram 3 etapas, descritas a seguir e apresentadas, na forma de fluxograma, na Figura 3: 1) pesquisa bibliográfica; 2) aquisição, seleção e tratamento das bases cartográficas; e, 3) atividades de campo e geoprocessamento. 
Figura 3. Fluxograma das atividades desenvolvidas.

Figure 3. Flowchart of activities.

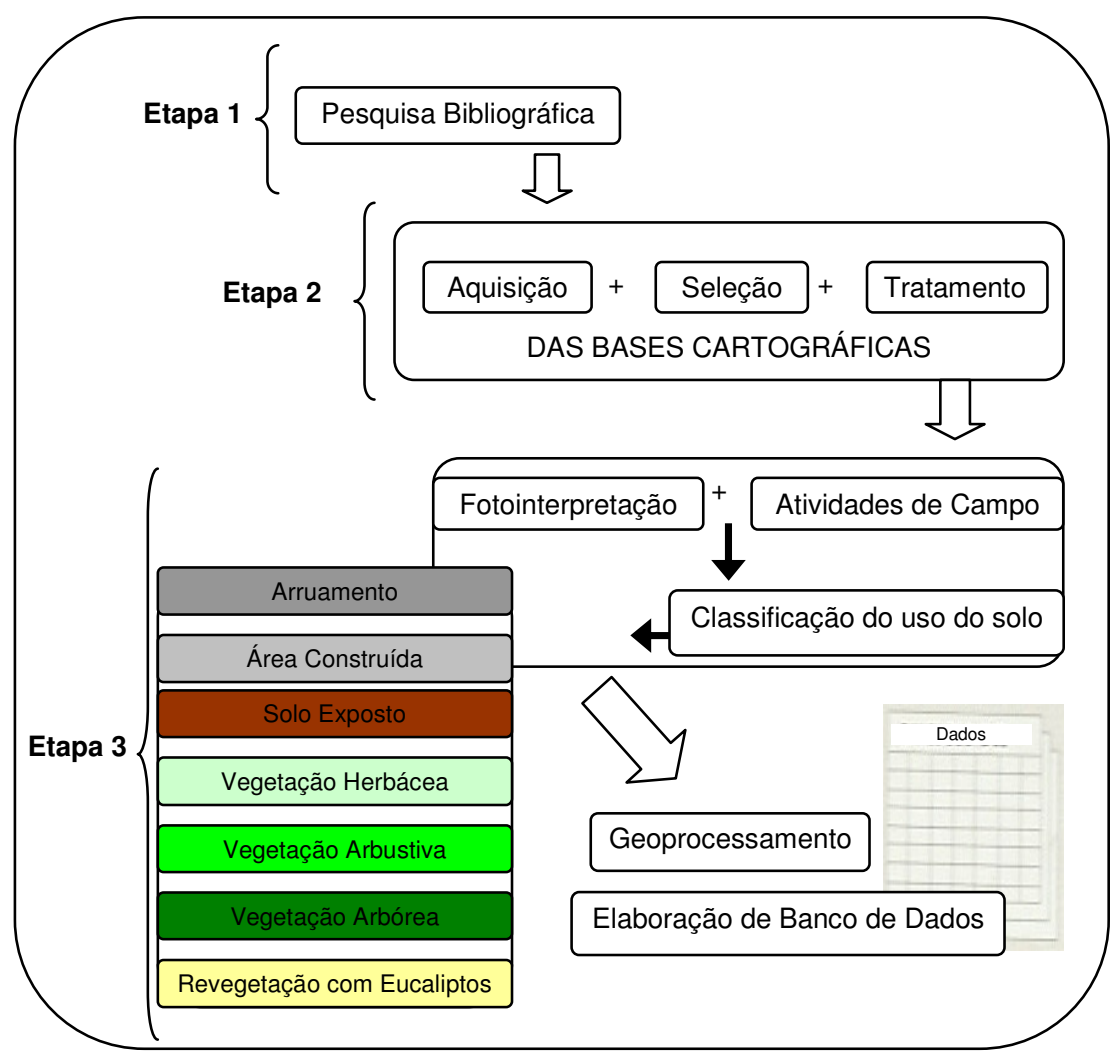

A etapa de pesquisa bibliográfica buscou agrupar o maior número de informações possíveis sobre a área, a fim de se estabelecer os procedimentos a serem adotados no estudo. Utilizou-se como referência diversos trabalhos e autores: trabalhos com a mesma temática, metodologias afins, referências sobre a área de estudo, na qual a Universidade Federal de Ouro Preto possui vasto acervo de trabalhos que ocorreram na região.

Já as etapas de aquisição, seleção e tratamentos das informações consideraram a adequabilidade das imagens de satélite (Quickbird 2003 e 2006) utilizadas para a fotointerpretação das bases cartográficas para os limites dos bairros e do perímetro urbano, cedidas pela Secretaria Municipal de Patrimônio de Ouro Preto (SMPOP). Foram utilizadas também, bases cartográficas em escala 1:500 contendo as curvas de nível de 10 em 10 metros, e os mapas do plano diretor de Ouro Preto (2006), disponibilizadas pelo departamento de Engenharia Ambiental da UFOP (DEAMB/UFOP).

Para o tratamento e ajuste das bases cartográficas, foi utilizado o programa ArcGIS 9.3 que se mostrou eficiente por ter fácil comunicação com outros programas e extensões 
como AutoCad, Excel, Photoshop, GPS TrackMaker, entre outros. Os ajustes realizados nestas bases seguem descriminados abaixo:

- Padronização das extensões dos arquivos (Shapfiles);

- Padronização do Datum (Córrego Alegre 23 sul).

- Ortorretificação das imagens Quickbird, 2003 e 2006 a partir da carta topográfica da cidade.

Durante a etapa de campo, concomitantemente com o geoprocessamento, foram visitadas, catalogadas e georreferênciadas, com o auxilio de um receptor GPS, todas as áreas verdes e áreas urbanizadas do núcleo urbano passiveis de acesso. Os trabalhos seguiram dois passos básicos:

- Identificação e quantificação das áreas de preservação permanente inseridas no perímetro urbano de Ouro Preto, estabelecidas de acordo com o Código Florestal - Lei Federal 4.771/65 (BRASIL, 1965) complementado com a Lei Municipal Complementar no 93 (OURO PRETO, 2011).

- Identificação, delimitação e classificação do uso do solo das áreas de preservação permanente (APP) em 7 tipologias: arruamento, área construída, solo exposto, vegetação herbácea, vegetação arbustiva, vegetação arbórea e áreas reflorestadas.

Para identificação e classificação do uso do solo optou-se pelo método da fotointerpretação das imagens Quickbird de 2003 e 2006. A fotointerpretação é o processo em que o interprete utiliza o raciocínio lógico, dedutivo e indutivo para compreender e explicar o comportamento de cada objeto contido nas fotos ou imagens. Em outras palavras, consiste em extrair informações de alvos da superfície terrestre com base na sensibilidade do interprete. De acordo com Figueiredo (2005), na interpretação visual são utilizados alguns elementos foto interpretativos como: textura, forma, tamanho, tonalidade ou cor.

Para o método de fotointerpretação das imagens, deve-se considerar a data das imagens trabalhadas (Quickbird 2003 e 2006), evitando assim, interpretações equivocadas à realidade (a de 2011), tendo em vista que a urbanização da área continuou a avançar.

A descrição das 7 tipologias adotadas a partir das fotointerpretações das imagens seguem descriminadas abaixo:

1. Arruamento - caracterizado por apresentar arruamento asfáltico, de paralelepípedo ou de terra.

2. Área construída - caracterizada por apresentar predominância de edificações comerciais, residenciais e industriais;

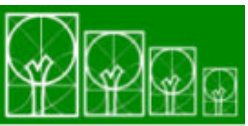

$\mathbf{S} \cdot \mathbf{B} \cdot \mathbf{A} \cdot \mathbf{U}$ Soc. Bras. de Arborização Urbana 
3. Solo exposto - caracterizado por apresentar predominância de solos sem cobertura vegetal;

4. Vegetação herbácea - caracterizada por apresentar predominância de vegetação de caule macio ou maleável, normalmente rasteiro, sem caule lenhoso.

5. Vegetação arbustiva - caracterizada por apresentar predominância de vegetação com indivíduos de baixo porte ou em fase de desenvolvimento.

6. Vegetação arbórea - caracterizada por apresentar vegetação com indivíduos de porte médio a alto.

7. Áreas reflorestadas - caracterizadas por apresentar dominância de espécies do gênero Eucalyptus spp.

\section{RESULTADOS}

De acordo com a legislação federal e municipal pertinente, o perímetro urbano de Ouro Preto possui atualmente $19,37 \mathrm{~km}^{2}$ de áreas legalmente protegidas no que se refere a margens de cursos d'água, declividade e topos de morros, o que representa $69 \%$ da área total do perímetro, como mostra a Figura 4.

Figura 4. Representação gráfica da distribuição das áreas de preservação permanente (APP) relativas aos topos de morro, hidrografia e declividade do perímetro urbano de Ouro Preto

Figure 4. Graphic representation of the distribution of permanent preservation areas (APP) on the hilltops, hydrography and slope of the urban area of Ouro Preto

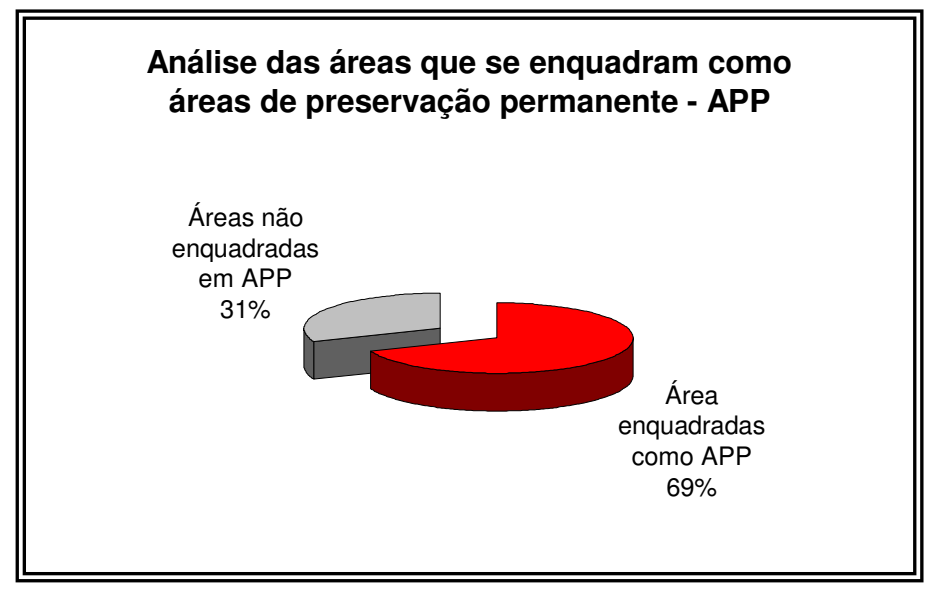


A Figura 5 apresenta a localização das áreas de preservação permanente (APP) inseridas no perímetro urbano de Ouro Preto (MG) e os seus respectivos usos do solo.

Figura 5. Mapa com a localização e a distribuição das áreas de preservação permanente (APP) relativas à hidrografia, declividade e topos de morro do perímetro urbano de Ouro Preto, e respectivas tipologias de uso do solo

Figure 5. Map showing the location and distribution of permanent preservation areas (APP) on the hydrography, slope and hilltops of the urban area of Ouro Preto, their types and land use

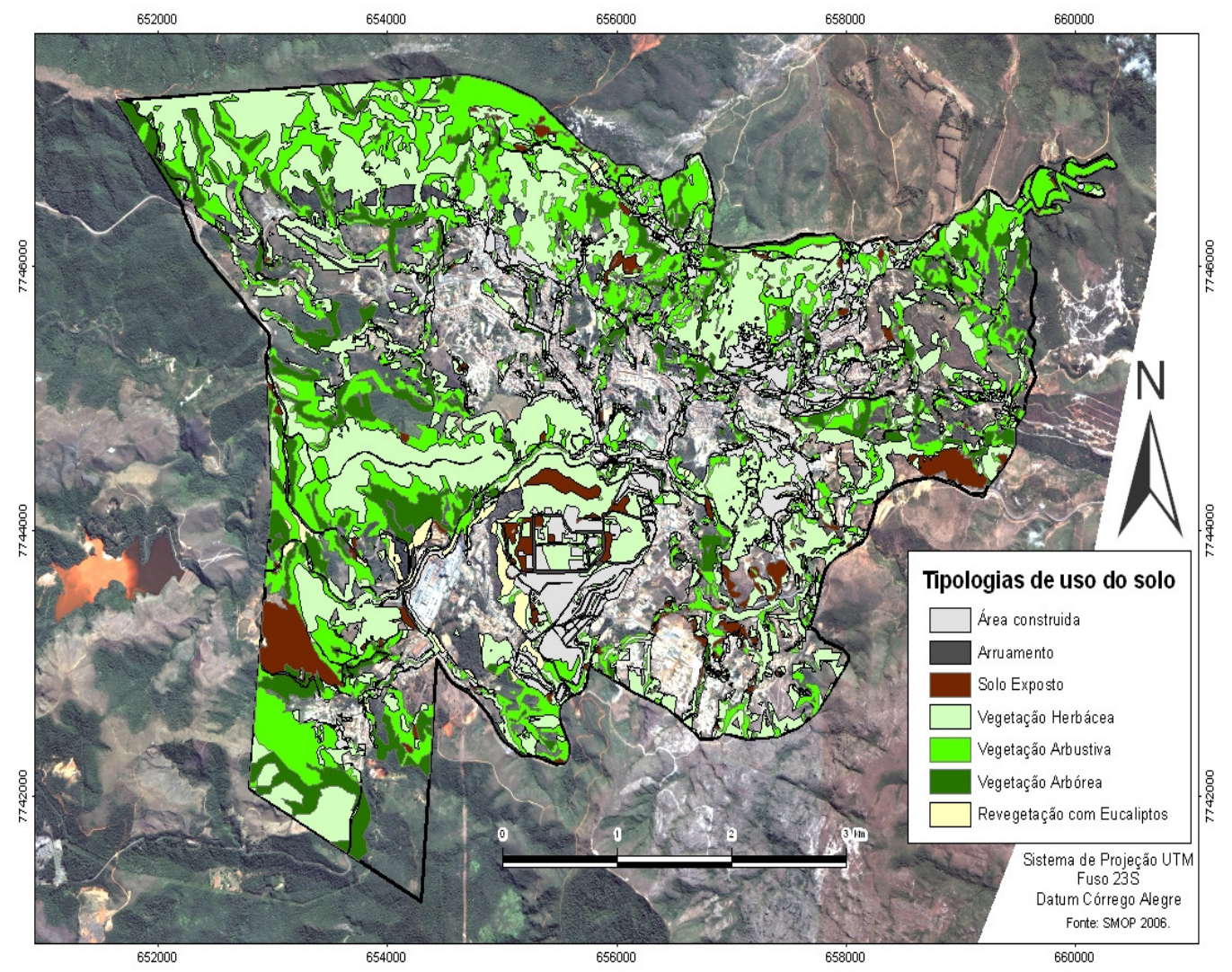

O uso do solo das áreas de preservação permanente (APP) para o perímetro urbano de Ouro Preto está representado na Tabela 1. 
Tabela 1. Uso do solo das áreas de preservação permanente (APP) relativas aos topos de morro, hidrografia e declividade do perímetro urbano de Ouro Preto

Table 1. Land use of permanent preservation areas on hilltops, hydrography and slopes on the urban perimeter of Ouro Preto

\begin{tabular}{l|c|r}
\hline Área total da APP & $\mathbf{1 9 . 3 7 8 . 9 8 4} \mathbf{~ m}^{2}$ & $\mathbf{1 0 0 \%}$ \\
\hline Arruamento & $669.228 \mathrm{~m}^{2}$ & $3 \%$ \\
\hline Área Construída & $2.054 .265 \mathrm{~m}^{2}$ & $11 \%$ \\
\hline Solo Exposto & $976.723 \mathrm{~m}^{2}$ & $5 \%$ \\
\hline Vegetação Herbácea & $7.691 .024 \mathrm{~m}^{2}$ & $\mathbf{2 9} \%$ \\
\hline Vegetação Arbustiva & $5.523 .283 \mathrm{~m}^{2}$ & $11 \%$ \\
\hline Vegetação Arbórea & $2.194 .446 \mathrm{~m}^{2}$ & $1 \%$
\end{tabular}

$\mathrm{Na}$ tabela 1 pode-se observar que 19\% $\left(3,70 \mathrm{~km}^{2}\right)$ das áreas de preservação permanente (APP) do perímetro urbano encontram-se antropizadas, constituído principalmente de áreas construídas, arruamentos e de solo exposto. Vale destacar que dos $81 \%$ de áreas verdes remanescentes, $40 \%$ encontram-se cobertas com vegetação herbácea, sendo algumas classificadas como campo rupestre, porém as demais demonstram que já foram bastante alteradas com a retirada de boa parte da mata nativa remanescente. Nessas áreas, observa-se a necessidade de realização de um enriquecimento vegetal com espécies arbóreas e arbustivas visando inibir a ocupação irregular das mesmas.

\section{DISCUSSÃO}

O estudo identificou as áreas verdes remanescentes e legalmente protegidas inseridas no perímetro urbano de Ouro Preto. De acordo com Loboda e De Angelis (2005), as referidas áreas proporcionam diversos benefícios, tais como, redução da poluição atmosférica, equilíbrio solo-clima-vegetação, redução de ruídos sonoros, melhoria da estética urbana, dentre outros. Além de garantir a preservação dos recursos hídricos, da estabilidade geológica e da biodiversidade, bem como o bem-estar da população (BRASIL, 1965).

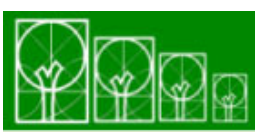


O perímetro urbano da cidade apresentou $69 \%\left(19,37 \mathrm{~km}^{2}\right)$ de suas áreas enquadradas como áreas de preservação permanente conforme estipulam as leis federais e municipais vigentes. Destas áreas legalmente protegidas, $19 \%\left(3,70 \mathrm{~km}^{2}\right)$ encontram-se antropizadas, constituído de áreas construídas, arruamentos e solo exposto. Diante desse quadro, o poder público municipal deveria fazer cumprir a lei, fiscalizando e cuidando das áreas verdes, que por imposição da lei deveriam ser mantidas intactas e protegidas.

A antropização destas áreas favorece inúmeros processos geoambientais locais, tais como a diminuição de infiltração de águas pluviais, o que faz aumentar o volume e a força das águas que não conseguem se infiltrar no terreno e nas fraturas e fendas das rochas que são muito comuns na superfície de Ouro Preto. Tais processos aumentam a capacidade de gerar processos erosivos podendo originar instabilidade e deslizamentos de massa, assoreamento dos corpos d'água, diminuição na qualidade dos recursos hídricos, variação do regime hídrico, problemas estes que se amplificam no período chuvoso.

A cidade de Ouro Preto possui em seu histórico acidentes envolvendo a antropização dessas áreas, sendo um dos mais graves o deslizamento de encostas ocorrido em 1979, inclusive com perda de vidas (PINHEIRO et al., 2003). Além de incidir diretamente sobre as pessoas, todos os fatores oriundos da antropização dos espaços, principalmente daqueles que deveriam ser preservados, implicam diretamente na redução da diversidade de espécies tanto da flora quanto da fauna, causando enormes prejuízos ao ecossistema local.

Este estudo analisou também a nova proposta de redação do Código Florestal em discussão no Congresso Nacional. Na simulação, verificou-se que com a aplicação das diretrizes propostas, ou seja, a extinção das áreas de preservação permanente (APP) de topos de morro e redução da faixa de preservação nas laterais de cursos d'água de $30 \mathrm{~m}$ para $15 \mathrm{~m}$, o perímetro urbano de Ouro Preto perderia $35,51 \%\left(6,88 \mathrm{~km}^{2}\right)$ de áreas atualmente consideradas protegidas.

$\mathrm{Na}$ Figura 6, pode-se observar que com a nova proposta de redação do Código Florestal ocorrerá uma perda de proteção de 2,57\% de área de vegetação arbórea, 9,50\% de área de vegetação arbustiva e 14,34\% de área de vegetação herbácea, representando $26,41 \%$ de áreas verdes sujeitas á supressão, com consequências diretas sobre a biodiversidade e áreas relevantes para a conservação, implicando em significativos prejuízos para o meio ambiente, qualidade ambiental e de segurança para a população, principalmente daquelas situadas em áreas irregulares, visto que a cidade já apresenta um longo histórico de acidentes de deslizamentos de massa, como os ocorridos em 1967, 1979, 1989, 1995 e 1997 (SOBREIRA e FONSECA, 2001).

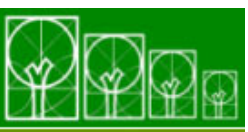

$\mathbf{S} \cdot \mathbf{B} \cdot \mathbf{A} \cdot \mathbf{U}$ Soc. Bras. de Arborização Urbana 
Figura 6. Representação gráfica da relação de perdas entre o Código Florestal vigente e a nova proposta de redação do mesmo, aplicado para o perímetro urbano de Ouro Preto

Figure 6. Graphic representation of the relationship between the actual Forestry Code and the new proposal of it showing how much it is going to reduce the permanent preservation areas, applied to the urban area of Ouro Preto

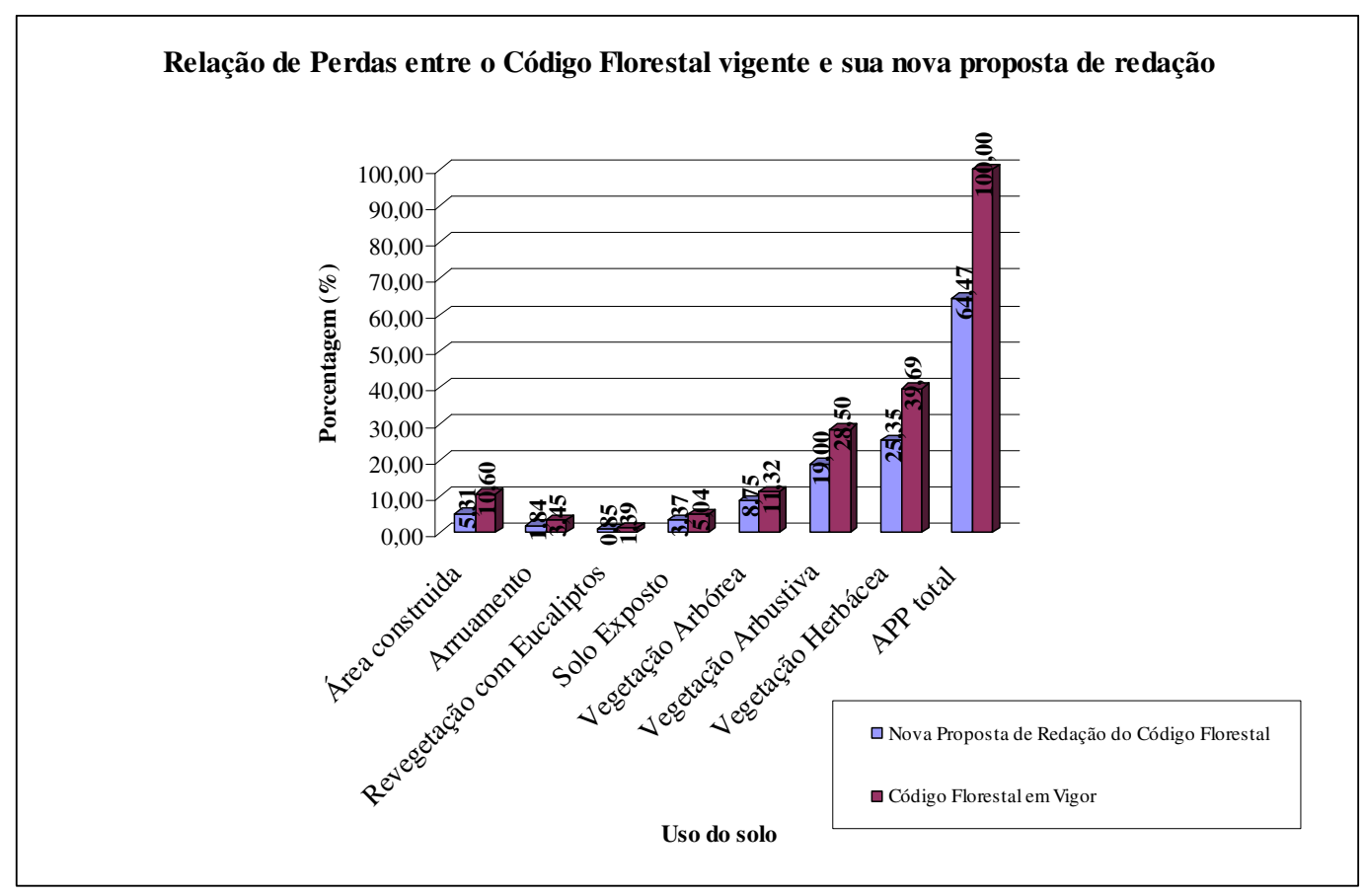

Além do mais, autores como Metzger et al. (2010) e Ab'Saber (2010), relatam que a nova redação da Lei Federal 4.771/65, favorecerá um aumento significativo das emissões de $\mathrm{CO}_{2}$, descumprindo o acordo firmado pelo país recentemente no Copenhagen Climate Conference 2009, onde foi estabelecido metas de redução ou limitação do crescimento das emissões de gases do efeito estufa até 2020. Se aprovada a nova proposta do Código Florestal, mais de 100.000 espécies deixarão de existir no Brasil, uma perda maciça que invalida qualquer compromisso com a conservação da biodiversidade. (METZGER et al., 2010). Em Ouro Preto, a nova proposta de redação do Código Florestal Brasileiro não terá aplicação, visto que a cidade apresenta a Lei Municipal Complementar N. ${ }^{\circ} 93$ (OURO PRETO, 2011) que é clara sobre as proibições e permissões no parcelamento de terrenos. 


\section{CONCLUSÕES}

As interpretações das imagens aéreas são úteis na análise espacial das áreas de preservação permanente (APP) e quando integradas ao SIG possibilitaram a combinação de vários planos de informação do uso do meio físico, inclusive como suporte para quantificar o uso do solo, principalmente os inadequados destas áreas.

Com a análise das imagens foi possível quantificar a área de estudo que compreende $27,9 \mathrm{~km}^{2}$, dos quais $14,5 \mathrm{~km}^{2}$ estão distribuídos entre os 38 bairros e $13,3 \mathrm{~km}^{2}$ são áreas verdes não ocupadas (zona de amortecimento ou cinturão verde). O perímetro urbano de Ouro Preto apresenta 24\% $\left(6,69 \mathrm{~km}^{2}\right)$ de áreas antropizadas e 76\% $\left(21,09 \mathrm{~km}^{2}\right)$ de áreas verdes. Além disso, permitiu identificar as áreas protegidas pela legislação federal e municipal, totalizando $19,37 \mathrm{~km}^{2}$ de APP, que representa $69 \%$ da área de estudo.

Percebe-se que em Ouro Preto, e isso não é realidade apenas local, vide recentes acontecimentos de deslizamentos de encostas e corridas de massa com centenas de mortes e desaparecidos na Serra Fluminense em 2010, deveriam se fazer cumprir as leis federais e municipais que estabelecem normas, restrições e condições para o parcelamento, ocupação e o uso do solo urbano. Cabe obrigatoriamente ao poder público local fiscalizar e cuidar das suas áreas verdes legalmente protegidas, as quais, muitas vezes, sem a devida atenção do administrador local, podem gerar riscos, inclusive à população.

O zoneamento geoambiental adequado das áreas urbanizadas associado à uma fiscalização efetiva do poder público pode preservar áreas de mananciais, conservando um recurso vital para o desenvolvimento das cidades além de evitar inúmeras catástrofes relacionadas à má utilização do espaço urbano, como deslizamentos, enchentes, assoreamentos, dentre outros.

O Poder Público municipal deve, em caráter de urgência, planejar e orientar a ocupação dos espaços, visto que as áreas construídas representam 18\% das APP relativas à declividade, $10 \%$ das APP relativas aos topos de morro, 9\% das APP relativas a nascentes e rios e $12 \%$ das APP relativas a lagoas, o que constitui risco potencial para a população, resultado da negligência e condescendência no que se refere à permissão de ocupação dessas áreas.

Com a aplicação da nova proposta de redação do Código Florestal em discussão no Congresso Nacional, o perímetro urbano de Ouro Preto perderia 35,5\% (6,88 $\left.\mathrm{km}^{2}\right)$ das suas áreas legalmente protegidas, porém a cidade possui legislação, a Lei Municipal Complementar no 93 (OURO PRETO, 2011), que resguarda suas áreas de preservação

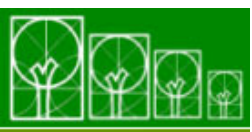

$\mathbf{S} \cdot \mathbf{B} \cdot \mathbf{A} \cdot \mathbf{U}$ Soc. Bras. de Arborização Urbana 
permanente. Porém, as demais cidades brasileiras que não possuem legislação específica estariam sujeitas a perdas de áreas verdes, caso aprovada a nova proposta do Código Florestal.

\section{AGRADECIMENTOS}

Ao Programa de Mestrado em Engenharia Ambiental - PROAGUA/UFOP e CNPq/Capes pelo apoio financeiro, e à Secretária do Patrimônio de Ouro Preto pelos dados cedidos para realização deste estudo.

\section{REFERÊNCIAS}

AB' SÁBER A. N. Criticas ao relatório de reformulação da legislação. Carta enviada a Câmara dos deputados. 16 de Junho de 2010.

BARBOSA JR., A. R. HIDROLOGIA. Ouro Preto, MG: Escola de Minas, Universidade Federal de Ouro Preto, (APOSTILA) 2006. 239p.

BRASIL. Leis e Decretos. Lei Federal no 4.771, de 15 de setembro de 1965. Institui o Novo Código Florestal Brasileiro. Brasília, DF. 1965.

BRASIL. Leis e Decretos. Resolução CONAMA n 303, de 20 de Março de 2002, dispõe sobre parâmetros, definições e limites de Áreas de Preservação Permanente. Diário Oficial da União, Brasília, DF. 2002.

BRASIL. Leis e Decretos. Lei Federal $\mathbf{n}^{\circ} \mathbf{7 . 5 1 1}$, de 07 de julho de 1986. Altera dispositivos da Lei 4.771, de 15 de Setembro de 1965, que institui o novo Código Florestal. Disponível em: <http://www.lei.adv.br/7511-86.htm>. Acesso em: 20 jun. 2006.

CASTRO, J. M. G. Pluviosidade e movimentos de massa nas encostas de Ouro Preto. 2006. 114 f. Dissertação (Mestrado em Engenharia Civil), Universidade Federal de Ouro Preto - UFOP, 2006.

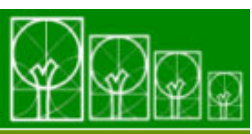


CAVALHEIRO, F. Arborização urbana: planejamento, implantação e condução. In: CONGRESSO BRASILEIRO SOBRE ARBORIZAÇÃO URBANA, 2,; ENCONTRO NACIONAL SOBRE ARBORIZAÇÃO URBANA, 5., São Luís, 1994. Anais. São Luis: Sociedade Brasileira de Arborização Urbana, 1994. p. 227-231.

CAVALHEIRO, F.; DEL PICCHIA, P.C.D. Áreas Verdes: conceitos, objetivos e diretrizes para o planejamento. In: CONGRESSO BRASILEIRO SOBRE ARBORIZAÇÃO URBANA, 1; ENCONTRO NACIONAL SOBRE ARBORIZAÇÃO URBANA, 4.,Vitória, 1992. Anais. Vitória: Prefeitura, 1992. V.1, p. 29-37.

DETZEL, V. A. Arborização urbana: importância e avaliação econômica. In: CONGRESSO BRASILEIRO SOBRE ARBORIZAÇÃO URBANA, 1; ENCONTRO NACIONAL SOBRE ARBORIZAÇÃO URBANA, 4.,Vitória, 1992. Anais. Vitória: Prefeitura, 1992. V.1, p. 39-52.

DETZEL, V. A. Avaliação monetária e de conscientização pública sobre arborização urbana; aplicação metodológica à situação de Maringá-PR In: CONGRESSO BRASILEIRO SOBRE ARBORIZAÇÃO URBANA, 2,; ENCONTRO NACIONAL SOBRE ARBORIZAÇÃO URBANA, 5., São Luís, 1994. Anais. São Luís: Sociedade Brasileira de Arborização Urbana, 1994. p. 49-65.

FIGUEIREDO, D. C. Aperfeiçoamento do Sistema de Previsão de Safras da CONAB. Brasília, 2005. Disponível em: <http://www.conab.gov.br>. Acesso em: 20/11/2010.

GOYA, C. R. Os jardins e a vegetação no espaço urbano: um patrimônio cultural. In: CONGRESSO BRASILEIRO SOBRE ARBORIZAÇÃO URBANA, 2,; ENCONTRO NACIONAL SOBRE ARBORIZAÇÃO URBANA, 5., São Luís, 1994. Anais. São Luis: Sociedade Brasileira de Arborização Urbana, 1994. p. 133-145.

GUZZO, P. Estudos dos espaços livres de uso público e da cobertura vegetal em área urbana da cidade de Ribeirão Preto, SP. 1999. 106f. Dissertação (Mestrado em Geociências). Instituto de Geociências e Ciências Exatas, Universidade Estadual Paulista, Rio Claro. 1999.

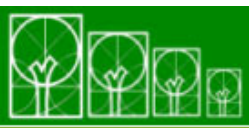

$\mathbf{S} \cdot \mathbf{B} \cdot \mathbf{A} \cdot \mathbf{U}$ Soc. Bras. de Arborização Urbana

REVSBAU, Piracicaba - SP, v.6, n.4, p.107-124, 2011 
HENKE-OLIVEIRA, C. Planejamento ambiental da cidade de São Carlos (SP) com ênfase nas áreas públicas e áreas verdes: diagnósticos e propostas, 1996. 181 f. Dissertação (Mestrado em Ecologia) - Universidade Federal de São Carlos. São Carlos, 1996.

IBGE, Instituto Brasileiro de Geografia e Estatística. Disponível em: <http://www.ibge.gov.br> Acesso em: 18 de novembro de 2010.

IGA, 1995b. Secretaria de Estado de ciência, tecnologia e meio ambiente. 1995a. Desenvolvimento ambiental de Ouro Preto - Microbacia do Ribeirão do Funil. Belo Horizonte, CETEC - Minas Gerais. 1995.

LIMA NETO, E. M.; RESENDE, W. X.; SENA, M. G. D.; SOUZA, R. M. Analise das áreas verdes das praças do bairro centro e principais avenidas da cidade de Aracaju - SE. Revista da Sociedade Brasileira de Arborização Urbana (SBAU), v. 2, n.1, p. 17-33, 2007.

LOBODA, C. R.; DE ANGELIS, B. L. D. Áreas verdes públicas urbanas: conceitos, usos e funções. Revista do Centro de Ciências Agrárias e Ambientais, Guarapuava, v.1, p. 125- 139. 2005.

METZGER, J. P.; LEWINSOHN, T. M.; JOLY. C. A.; VERDADE, L. M.; MARTINELLI, L. A.; RICARDO, R. R. Brazilian law: Full speed in Reverse? Science, vol. 329, p. 276-277. 2010.

MILANO, M. S. Planejamento da arborização urbana: relação entre áreas verdes e ruas arborizadas. In: ENCONTRO BRASILEIRO SOBRE ARBORIZAÇÃO URBANA, 3. Curitiba, 1990. Anais, Curitiba: FUPEF do Paraná,1990. p. 60-71.

MILANO, M. S. A cidade, os espaços abertos e a vegetação In: CONGRESSO BRASILEIRO SOBRE ARBORIZAÇÃO URBANA, 1; ENCONTRO NACIONAL SOBRE ARBORIZAÇÃO URBANA, 4.,Vitória, 1992. Anais. Vitória: Prefeitura, 1992. V.1, p.3-13.

MILANO, M. S. Arborização urbana: Plano Diretor. In: CONGRESSO BRASILEIRO SOBRE ARBORIZAÇÃO URBANA, 2,; ENCONTRO NACIONAL SOBRE ARBORIZAÇÃO 
URBANA, 5., São Luís, 1994. Anais. São Luis: Sociedade Brasileira de Arborização Urbana, 1994. p.207-215.

OLIVEIRA, L. D. Ocupação na área urbana de Ouro Preto de 1950 a 2004 e atuais tendências. 2010. 123f. Dissertação (Mestrado em Geologia) - Universidade Federal de Ouro Preto, Minas Gerais, 2010.

OURO PRETO. Leis e Decretos. Lei Municipal Complementar $n^{\circ} 93$ de 21 de Janeiro de 2011. Estabelece normas e condições para o parcelamento, a ocupação e o uso do solo urbano no Município de Ouro Preto. Câmara Municipal, Ouro Preto, MG, 2011.

PINHEIRO, A. L.; SOBREIRA, F. G.; LANA, M. S. Influência da expansão urbana nos movimentos em encostas na cidade de Ouro Preto, MG. REM - Revista da Escola de Minas, Ouro Preto 56(3): p.169-174, Jul. Set. 2003.

SATTLER, M. A. Arborização urbana e conforto ambiental. In: CONGRESSO BRASILEIRO SOBRE ARBORIZAÇÃO URBANA, 1; ENCONTRO NACIONAL SOBRE ARBORIZAÇÃO URBANA, 4., Vitória, 1992. Anais. Vitória: Prefeitura, 1992. V.1, p. 15-28.

SILVA FILHO, D. F.; BORTOLETO, S. Uso de indicadores de diversidade na definição de plano de manejo da arborização viária de Águas de São Pedro - SP. Revista Árvore, Viçosa-MG, v.29, n.6, p. 973-982, 2005.

SOBREIRA F. G. e FONSECA M. A. Impactos físicos e sociais de antigas atividades de mineração em Ouro Preto, Brasil. Geotecnia, Lisboa, n.92, p. 5-28. 2001. 